\title{
ORIGEN Y EFECTOS DE LAS NORMAS DE CALIDAD EN LA ADMINISTRACIÓN PÚBLICA
}

\section{ORIGIN AND IMPACT OF QUALITY STANDARDS ON PUBLIC ADMINISTRATION}

\author{
DIANA VICHER \\ Universidad Nacional Autónoma de México, México \\ mdvicherg@yahoo.com.mx
}

\begin{abstract}
RESUMEN
Este trabajo versa sobre la trayectoria que la noción calidad, en su acepción actual, ha seguido dentro de la administración pública. Se revisa su origen y los cambios que ha presentado el concepto. Particularmente, se hace énfasis en los hechos y el contexto que facilitaron que la calidad se erigiera como un eje de transformación que auguraba un mejoramiento sustancial en la forma de prestar servicios, desde la realización de cambios en los procesos internos de la administración pública, siguiendo con la aplicación de los procedimientos que las organizaciones lucrativas utilizaron para eficientar el desempeńo, y terminando con las cartas de calidad en el servicio. En este tenor también se resalta la tarea que han desempeñado las organizaciones internacionales que han fomentado los modelos y estándares de calidad, con énfasis particular en la Organización Internacional de Estandarización (ISO), para conocer su naturaleza y sus fuentes de legitimidad y autoridad para certificar a la administración pública. Finalmente, se revisa la aplicación de la calidad y las normas de calidad en la administración pública mexicana.
\end{abstract}

Palabras clave: Gestión de la calidad, Modelos de calidad, Administración pública, ISO.

\begin{abstract}
This work focuses on the path that the notion quality - in its current meaning has followed within public administration. It reviews the origin and changes that the concept has undergone. Particularly, it emphasizes the facts and the context which enabled quality to raise as a transformation axis which foresaw a substantial improvement in the way of providing services, from the changes made to internal public administration processes, following with the application of the procedures which profit organizations used to improve their performance efficiency, and ending with the quality charters of the service. In this vein, is also highlights the work performed by international organizations which have promoted models and quality standards, with particular emphasis on the International OrganizaRevisTa de Gestión Pública

Volumen I, Número 1
\end{abstract}

ISSN 0719-1820

pp. $127-164$ 
tion for Standardization ISO, to know their nature and sources of legitimacy and authority to certify public administration. Finally, we review the implementation of quality and standards of quality in the Mexican public administration.

Keywords: Quality management, Quality models, Public administration, ISO. 
La creencia ingenua en la posibilidad de fórmulas científicas de validez absoluta para regir la administración pública encuentra terreno fértil en países donde la mala calidad de la política coincide con la falta de estudio riguroso del gobierno.

Pedro Muñoz Amato, 1954.

\section{INTRODUCCIÓN}

Las medidas de calidad aplicadas desde finales de la década de 1980 en la administración pública, son parte de las reformas que se realizaron a la administración pública por medio de la Nueva Gerencia Pública. La calidad aplicada a la administración pública muestra una bifurcación en dos direcciones, la primera se refiere a mejorar la percepción del consumidor-cliente-ciudadano, mientras que la otra se dirige a los aspectos internos, o bien, al mejoramiento de los procesos y procedimientos, por la vía del estableciendo de la gestión de calidad. Así pues, por un lado se distinguen las guías de actuación como las cartas de servicio o de compromiso al ciudadano, mientras que por el otro, la aplicación y uso de estándares de calidad como las normas ISO.

Los modelos de calidad, los premios de calidad y los estándares internacionales han sido promovidos por agrupaciones privadas, particularmente por ingenieros y empresarios privados tanto de Europa como de los Estados Unidos. Inicialmente, sólo estaban dirigidas al sector privado pero progresivamente se introdujeron en las organizaciones públicas al abrir los premios de calidad a las organizaciones públicas. De manera simultánea, las normas ISO se constituyeron como una herramienta que también fue adoptada y adaptada desde las organizaciones privadas.

En México, como en muchos países, los modelos y estándares de calidad han tenido gran difusión, aceptación y aplicación, pero la naturaleza compleja del fenómeno y los efectos que conlleva hacia la administración pública, justifica continuar explorando esta temática con la finalidad de establecer otras interrelaciones de elementos que coadyuven a continuar abonando en el conocimiento relativo a los alcances e implicaciones de las iniciativas de calidad en la administración pública, así como del uso de las normas ISO.

\section{IRRUPCIÓN DE LA CALIDAD EN LA ADMINISTRACIÓN PÚBLICA}

Aunque de manera creciente pareciera que es un tema que aparenta poco a poco diluirse, la Nueva Gerencia Pública, integrada por una conjunción de elementos económicos, empresariales y gerenciales, sigue estando presente a través de las semillas que se esparcieron, y entre las cuales encontramos el enfoque de "orientación al cliente". Esta noción que hoy día ya no tiene mayor eco, cobijó a otras que 


\section{VICHER}

siguen subsistiendo al amparo del presupuesto público, y entre éstas encontramos a la calidad del servicio, desde la cual se han desprendido las certificaciones de calidad ISO.

La vinculación entre la orientación al cliente y la calidad en el servicio está plasmada en mayor o menor medida en los documentos que promovieron el modelo neogerencial. La correlación es particularmente visible cuando se señala que la calidad en el servicio radica en el grado de satisfacción aportado por la naturaleza del resultado y la prestación del servicio efectuado a los objetivos del gobierno y, eventualmente, a las necesidades del cliente (OCDE 1997: 333). Y en este tenor se concluyó que "La irrupción del ciudadano [cliente] como unidad de referencia del servicio público y no la burocracia irrepresentativa como beneficiaria primaria de la gestión pública ubica el tema en el campo de la gestión de la calidad". Es de este modo que la orientación de las administraciones públicas hacia la calidad se observaba como un aspecto fundamental para que ésta pudiera lograr su modernización. Se asumía que:

En tanto que "calidad" sea entendida como la capacidad de un bien o servicio de satisfacer las necesidades explícitas o implícitas del usuario inmediato o último beneficiario de ese bien, es decir, el ente (persona física o jurídica) final por el cual se justifica una acción y el que, a su vez, justifica la existencia del proveedor de dicho bien o servicio (Malvicino 2001: 4).

Empero, hay que poner de manifiesto desde ahora que la existencia del gobierno y su administración pública no tienen o deben su razón de ser o legitimación sólo a la prestación de servicios, aunque frecuentemente a ello se haya reducido su existencia denominándolos simplemente sector público.

Cabe también dejar sentado que la mayoría de las ideas y nociones que se adoptaron para crear los "novedosos" modelos de reinvención del gobierno y la administración pública, así como la calidad, calidad total y sus derivados, como los ISOs, tuvieron campo fértil gracias a las condiciones mundiales que la globalización creó, ya que abrió nuevos horizontes a actores que irrumpieron con gran peso desde diferentes organizaciones internacionales.

Paralelamente, también se habían estado desarrollando nuevos modelos de organización y funcionamiento en la empresa privada, mismos que se configuraron como producto de los cambios económicos mundiales emanados desde las ideas de la economía neoclásica, donde la quintaesencia la constituye la resolución de uno de los dilemas que provocaron la crisis de la economía clásica: la paradoja del valor ${ }^{1}$.

La paradoja del valor que los economistas clásicos no pudieron resolver (valor de uso y valor de 
Lejano y extraño parecería todo esto, no obstante, como ya se ha documentado, los cambios realizados sobre el papel del Estado y la administración pública, están estrechamente vinculados a los cambios que se generaron en el equilibrio de la balanza, cuando el peso del mercado se impuso sobre el del Estado. Encontrar el hilo conductor en toda y cada una de sus hebras no es simple, pero intentaremos jalar la que corresponde a cómo la noción calidad, que surge en este contexto, se incorporó dentro de la administración pública, y a los alcances de estos hechos.

Pues bien, los autores neoclásicos resolvieron la paradoja del valor yendo más allá de lo que se entendió como el valor intrínseco de los objetos, y lo situaron más allá del mundo material (lo objetivo), y lo llevaron al ámbito subjetivo, básicamente ubicado en ámbito de los deseos y anhelos de los individuos respecto de los objetos. Esto es: un objeto es valorado, no por los materiales de que está hecho, ni por el trabajo que se empleó para elaborarlo, sino por la apreciación que del mismo tenga el individuo.

Esto significó un cambio en el enfoque económico, que de situarse en la producción se traslada hacia el comercio, o bien, en un cambio de foco de atención que de estar colocado en la oferta se traslada hacia la demanda (el mercado). En términos simples esto se traduce en que ya no será el productor quien decida qué producir, ese conocimiento lo tienen los vendedores y los gerentes que son quienes están en contacto con los clientes. Así que estos últimos son quienes auscultarán en el mercado para conocer qué es lo que desean y anhelan los clientes, para así diseñar y ofrecer los productos con las características que señala el mercado ${ }^{2}$. Así pues, el valor de los objetos o bienes estará en función de las valoraciones del consumidor, y también de aquí se desprende la orientación al cliente.

Este ideario económico del nuevo liberalismo económico, tuvo su origen en los economistas Leon Walras, Stanley Jevons y Carl Menguer, pero su auge no se logró sino bajo el auspicio de la Sociedad Montpelerin, liderada por Frederick Hayek, (cuyo antecedente fue la reunión de Paris -Coloquio- presidida por Walter Lippmann en 1937), tuvo que esperar a que terminara la Segunda Guerra Mundial para establecerse como un cuerpo articulador de dicho pensamiento, que crecientemente tomaría gran fuerza, sobre todo cuando sus adeptos empezaron a formar parte de las principales organizaciones internacionales, los bancos centrales, y los ministerios de hacienda y economía, principalmente.

Estas renovadas ideas de economía de mercado constituyeron la base que nutrió el bagaje de las transformaciones que habrían de producirse en la industria y la empresa privada; conllevando una perspectiva muy diferente sobre cómo

cambio) se retrata en el pan y los diamantes: ¿̨por qué?, si el primero es más útil, los segundos valen más.

2 Véase Guerrero (2004: 72-82). 
deberían organizarse, funcionar, producir y vender las empresas privadas. De modo que se realizaron grandes cambios dirigidos a tener mayores acercamientos al cliente para saber qué desea comprar y consumir, y con qué características. Entonces, la empresa se organizaría en función de observar hacia afuera de sí misma para captar con mayor nitidez los deseos de los individuos ${ }^{3}$.

Bajo el énfasis de interés hacia la demanda -mercado-, operaron transformaciones sustanciales en las ideas sobre cómo buscar la rentabilidad, de modo que para ser exitosa, la empresa privada procedió a realizar cambios en su naturaleza, básicamente en cuatro aspectos: dinámica de la corporación (estudia lo que sucede fuera de sí misma, ausculta el sentir y la opinión de los clientes y no clientes); reducción de su tamaño ${ }^{4}$; reestructuración organizativa (dado que se dejó el flujo de cosas para adoptar el de información, los niveles administrativos pudieron reducirse); y transformación de la condición laboral de su personal. La gerencia se tornó en una mercancía que se puede adquirir en el mercado y se adoptó la práctica de contratar por fuera (Guerrero 2004: 37-41). Con el tiempo y en la coyuntura propicia, estas ideas también se harían extensivas a la administración pública para "reformarla y adaptarla" a los nuevos tiempos.

El ambiente favorable para aplicar estas ideas al Estado y la administración pública, se confeccionó con una sucesión de hechos que explican cómo se fue gestando el escenario que hizo posible el ascenso y extensión del espacio de actuación del mercado, en detrimento de la actuación del Estado. Entre los años que van de finales de la década de 1960 y el inicio de la década de 1970, se presenció progresivamente la ruptura de los Acuerdos de Bretton Woods ${ }^{5}$, con los que se había establecido un orden financiero internacional en 1945. Esto conllevó tres efectos muy importan-

\footnotetext{
3 No obstante, tal como lo han documentado economistas como John Galbraith, en realidad esa orientación al cliente no es tal, ni tampoco el cliente tiene información en la misma medida en que la posee la empresa o el vendedor, más bien, siempre está en desventaja y de hecho es manipulado con relación a sus decisiones sobre lo que compra (Galbraith 1972: 29, 249, 256, 259-264 y 268).

4 Se encontró que tamaño no era sinónimo de éxito, sino que se requieren estructuras distintas, en consonancia con sus diferentes propósitos: pequeñas y grandes, especializadas y generales. Pero, sobre todo, la reducción se produjo dado que en la década de 1960 la reducción fue impulsada por fuerzas nuevas como las alianzas, las fusiones, las adquisiciones y los desposeimientos. En el fondo, las empresas se habían convertido en grandes corporativos cuya propiedad y riesgos no podían seguir perteneciendo a un solo (una familia) o a muy pocos propietarios, sino que ahora estaría en manos de diversos accionistas. De aquí también se desprendió la denominada excelencia empresarial, caracterizada por ocho atributos: énfasis en la acción, proximidad con el cliente (se aprende del cliente, pues estas empresas brindan calidad y servicio), autonomía y empresarialidad, productividad a través de las personas, manos a la obra, zapatero a tus zapatos, formas simples, personal reducido, y estira y afloja simultáneo (Guerrero 2004: 37-41).

5 Desde principios de la década de 1960, los Estados Unidos empezaron a tener en circulación más dólares que reservas en oro. En 1965, se negó a pagar en oro a petición del gobierno francés, lo que llevó a que en 1967 Francia y Alemania renunciaran a reclamar la convertibilidad del dólar (Correa 1998: 102).
} 
tes como son: la hegemonía del dólar, el cambio en el papel del Fondo Monetario Internacional (FMI) y el Banco Mundial (BM) y la desregulación de los mercados financieros. Hoy ya no es ningún misterio que estos hechos también coinciden con el ascenso de los miembros (y sus alumnos) de la Sociedad Montpelerin tanto a las universidades (Chicago, Virginia, Instituto Adam Smith), como a los organismos internacionales (FMI, BM), y sobre todo a los bancos centrales y ministerios de Economía y Hacienda de los diferentes países de todo el mundo.

A finales de la década de 1970 los capitales de los bancos comerciales, ya desregulados, no reprimidos, estaban realizando operaciones lucrativas, mediante préstamos a los países, particularmente los países en desarrollo tomaron créditos con interés variable y a corto plazo -un proceso incentivado por el BM y el FMI-, lo que llevó directamente a la crisis de deuda de la década de 1980 que, acompañada de la recesión en los países desarrollados, creó el marco perfecto para que el clamor (en un mundo que se estaba caracterizando por la derechización de las clases dirigentes) por la reducción del papel del Estado cobrara gran fuerza y se constituyera en la modernización del Estado, entendida como su minimización. Ya conocemos de sobra la primera etapa que consistió en la privatización de empresas públicas.

Para principios de la década de 1980 los mercados financieros desregulados, que acentuaron su fase parasitaria, pronto empezaron a mostrar su inestabilidad, dada su natural búsqueda de lucro, pero en aquél momento la crisis no se relacionó de ninguna manera a este factor sino a los estados mal administradores ${ }^{6}$. Cierto es que los estados hicieron su parte, y que las necesidades de sus sociedades estaban en aumento, pero también lo es el hecho de que, formalmente desde 1971, el mundo ya no estaba funcionando bajo el modelo keynesiano, pues se había roto Bretton Woods, ni tampoco es un absoluto el que la crisis sólo se produjo por el Estado de Bienestar, pues el alza de las tasas, efectuada en 1979 hizo su parte, con la ganancia que profundizó y prolongó los efectos de la deuda ${ }^{7}$.

Hacia el futuro, dados los problemas económicos generalizados y los compromisos adquiridos:

6 Esta situación no ha sido muy enfatizada, pero fue un hecho que los bancos comerciales otorgaron los préstamos a tasas variables y a cortos plazos, cuando los gobiernos necesitan todo lo contrario. Si bien este primer ensayo se corrigió, el error fue cobrado a la población de los países en desarrollo, el BM y el FMI se aseguraron de ello.

7 En la década de 1970 se registró una fuerte caída en la tasa de ganancia y un crecimiento de la inflación, que abarataba el costo de los préstamos, desvalorizaba las deudas y los haberes establecidos en unidades monetarias. Las tasas de interés reales eran negativas o débiles, y las transferencias de riqueza de los acreedores se dirigían a empresas no financieras. La distribución de dividendos estaba en un nivel muy bajo. Ante esta situación, las finanzas decidieron frenar la inflación para proteger sus ingresos y sus patrimonios a fin de restablecer las pretensiones de los accionistas sobre las ganancias. Así, la inflación se combatió por medio del alza en las tasas de interés en 1979 (Duménil y Lévy 2007: 107, 110). 
(...) la nueva forma del Estado estaría definida por la misión, razón y práctica «empresarial» de las relaciones entre la sociedad y el Estado, que procura establecer la simplicidad en las estructuras y procedimientos, y la autonomía en las unidades operativas, donde la flexibilidad y autonomía se invocan como ejes de una acción pública selectiva, eficaz y eficiente. A este propósito se generó una difusión de principios tales como costo-beneficio, calidad de la prestación del servicio, información al cliente y el concepto global de servicio, con los que se buscó reconvertir a las estructuras y organizaciones estatales en empresas; a sus gobernantes en gerentes; y a sus ciudadanos en clientes (...) la responsabilidad administrativa, la orientación del desarrollo, el financiamiento de las políticas públicas, el acceso a la información, la distribución del ingreso y la fiscalización social, quedan sumidas por la aplicación técnica de conceptos y procedimientos tales como "gerencia pública», "calidad total», "gestión estratégica» (Medellín 1994: 11, 23).

\section{CALIDAD: ELEMENTO DE LA NUEVA GERENCIA PÚBLICA}

La orientación al cliente, la privatización y el mercado son las materias primas con las que se construyó la Nueva Gerencia Pública ${ }^{8}$. La calidad se ubica particularmente en el enfoque empresarial-gerencial que entre otros elementos comprende la flexibilización como transferencia de competencias: dejar gerenciar a los gerentes, la atención a resultados y el mejoramiento de la relación calidad/precio. También en la gerencia por objetivos y resultados, que engloba el diseño de objetivos por resultados, la formulación de estándares explícitos con medidas precisas de rendimientos, y la definición cuantitativa de metas e indicadores de éxito.

El lugar que calidad ocupa dentro de la NGP es patente en tres de los ocho ejes de cambio que dispuso?:

- Garantizar los resultados, el control y la responsabilidad.

- Establecer acuerdos de resultado: cartas por las que una agencia se compromete a prestar a sus clientes un nivel o una calidad de servicios

\footnotetext{
8 Los otros dos componentes son la competencia (mercados internos, facturación de servicios a usuarios, mercados de derechos de propiedad, bonos, constitución en sociedad, y contratos por fuera), y la agenciación (transformación de las formas de organización), medio que permitirá realizar la separación entre política y ejecución: establecer la disociación entre el diseño y la ejecución de las políticas: "agencias ejecutivas" para permitir la separación entre ministros (resultado de políticas) y funcionarios (encargados de ofrecer productos). Los ministros compran productos (servicios y hasta consejos) a sus ministerios (Guerrero 2004: 58-69).

9 Los restantes cinco son: transferir competencias, introducir más flexibilidad, desarrollar la competencia y ampliar las opciones, mejorar la gestión de los recursos humanos, optimizar el uso de la informática, y reforzar las funciones de dirección del nivel central (OCDE 1997: 70).
} 
Origen y Efectos de las Normas de Calidad en la Administración Pública

específicos (OCDE 1997: 82).

- Aplicación de indicadores de resultados en la calidad de los servicios. Prestar un servicio abierto a las necesidades del público.

- Participación de los ciudadanos, permitirles escoger en su condición de consumidores.

- Formulación de normas de servicio como las "cartas del usuario o cartas de calidad de los servicios públicos".

Mejorar la calidad de la reglamentación.

- Innovación en la aplicación de normas: recurrir a terceros para certificar el respeto a la reglamentación.

- Establecer normas expresas de calidad.

- Normas de uso como la estabilidad, previsibilidad, claridad, sencillez y accesibilidad. Normas de diseño como la flexibilidad y la compatibilidad con otros reglamentos y las normas internacionales (ISO) (OCDE 1997: 156).

Estas medidas estarían apoyadas en técnicas de mejora de la calidad como la Gestión de la Calidad Total que se enfoca en la calidad en todos los niveles y campos de actividad de una organización (OCDE 1997: 107-114).

Aunque la Nueva Gerencia Pública tuvo diferentes nombres como gobierno empresarial (o reinvención del gobierno de Osborne y Gaebler 1994), modelo posburocrático (Barzelay 1992) y de orientación al cliente (OCDE); éste último fue el que mayor relevancia tuvo. De hecho, en los documentos donde se plasman los elementos de los otros modelos de Nueva Gerencia Pública no se realiza ningún tratamiento articulado sobre el tópico calidad, aunque Osborne y Gaebler le dedican dos páginas, (Osborne y Gaebler 1994: 253 y 258), pero quienes han escrito al respecto han encontrado implícitamente la relación cuando se refieren al cambio de orientación de la administración pública ${ }^{10}$.

(...) estos gestores descubrieron que las diversas ideas y propuestas agrupadas entorno del concepto de Calidad Total, o en sus múltiples variantes de gestión de la calidad, permitían armar un sistema de gestión público coherente con los objetivos de hacer una administración pública más receptiva. (...) Al Gore constata que "los gobiernos eficaces y emprendedores insisten en la satisfacción del cliente”. Esta

\footnotetext{
10 Barzelay afirma que "las ideas y la práctica gerencial en el sector privado ha cambiado el énfasis del alto volumen y la producción estandarizada para enfatizar la alta calidad y la producción orientada al consumidor". Y que "muchos gobiernos han competido para ganar el premio presidencial de la calidad y muchos más han al menos adoptado los principios de gerencia de la calidad total" (Barzelay 1992: 28). Osborne y Gaebler tratan el tema al final de su texto al señalar que las organizaciones que utilizan la administración de la calidad total de Deming, lo que hacen es evaluar constantemente sus procesos internos para ver dónde yacen los problemas y corregirlos, pero que "la buena administración no es un fin en sí mismo" (Osborne y Gaebler 1994: 489).
} 
afirmación de Al Gore, aunque sea una lectura parcial del concepto de receptividad, sirve para destacar la importante penetración que los conceptos de gestión de la calidad han tenido en el sector público (López 1998: 15).

También se encontró que "en muchos sentidos, el movimiento y concepto de Reinvención del Gobierno tiene su génesis en los principios relacionados con la Administración de la Calidad Total (ACT)".De igual modo, se ha señalado que el traslado del enfoque de calidad hacia los gobiernos se desprendió de las innovaciones de gobiernos locales en Estados Unidos, en California en concreto ${ }^{11}$. Pero, sobre todo, que las herramientas y sistemas de medición del desempeño surgieron de las experiencias en el sector privado (Pasha 2003: 48-49).

El tratamiento más claro y concreto del tema se puede encontrar en los documentos de la OCDE que promovieron el modelo de orientación al cliente. En primer lugar está el informe de 1987, La Administración como Servicio, el Público como Cliente, que analiza la calidad de la interacción entre los miembros de la sociedad y la administración, pues la calidad de esa relación es factor determinante de la eficacia de la política, así que esa relación debe mejorarse (OCDE 1991: 18).

La calidad de la interacción (o de la relación) se colocó en función del contenido de la operación, como se denominó a servicios: la expedición de un permiso de conducir, la concesión de una ayuda de inversión o la inscripción para beneficiarse de una prestación social. Entonces, el foco de atención se dirigió a estudiar la organización de la administración pública en tanto que influye en la evaluación que hace el público de la calidad de sus relaciones con el Estado. En este sentido la ineficacia, el papeleo, la insatisfacción o la falta de amabilidad son los renglones que deberían ser corregidos, a fin de mejorar la calidad de la relación entre los miembros de la sociedad y la administración. De allí se infirió que para mejorar la calidad de los servicios prestados, los gobiernos tendrían que reformar la gerencia de la administración pública a fin de abandonar la noción de relación entre administrador y administrado para asumir que la administración es un servicio cuyo cliente es el público (OCDE 1991: 19).

Aquí entran a escena las iniciativas de calidad en el servicio que según la OCDE estarían dirigidas a poner mayor énfasis en el rendimiento, colocándose un paso delante de las reformas que se restringieron al apego a las reglas y procedimientos prescritos (OCDE 1996: 11). Esta organización ubicó el origen de las

\footnotetext{
11 Hoy día resultan reveladores los efectos que ha tenido la experimentación con las "innovaciones" en el gobierno local y los efectos que puede tener la excesiva confianza en el libre mercado. En 2003, el déficit presupuestario de California registraba 12 mil millones de dólares, y para 2009 el Estado afrontaba ya 24,3 mil millones de dólares y desde varios años antes un alto índice de desempleo (Weiss 2009).
} 
iniciativas en las respuestas que se generaron ante las presiones derivadas de los recursos del presupuesto, de modo que la mejora de los servicios permitiría reducir los costos; la calidad también se justificaba pues se refería que el público era más demandante, y que "los cambios en la teoría de la administración en el sector privado", podían transferirse al sector público. (OCDE 1996: 12, 21).

Las "iniciativas de calidad o declaraciones de normas de servicio", son las cartas del ciudadano, cartas para usuarios de servicios públicos, iniciativas de normas de servicio, las cartas de calidad de los servicios públicos o el establecimiento de observatorios de calidad, entre otros. Mundialmente hablando, el auge de estas iniciativas se registró en 1996, y aquí entra la Carta Iberoamericana de la Calidad en la Gestión Pública, que fue adoptada tardíamente, en 2008, pero que dio nuevos bríos a este tipo de iniciativas en el continente.

Para lograr la calidad en el servicio se consideró utilizable la Gerencia de la Calidad Total (Total Quality Management, TQM), para la evaluación y mejoramiento continuo de todos los procesos al interior de las instituciones ${ }^{12}$ (OCDE 1996: 39). Sus cuatro principios generales son: la comprensión y satisfacción de los requerimientos de los clientes, la noción de que todos los que forman parte de una organización son responsables de la calidad, que a todas las personas dentro de la organización se les debe tratar como clientes, y que la prosecución de la calidad es un proceso que nunca termina.

La herramienta relacionada con el mejoramiento de la calidad del servicio es la certificación o normas de calidad en el servicio, como las de la serie ISO-9000 y otras. La ventaja que se atribuyó de la certificación es realizada por un "tercero externo y neutral", independiente, que fija requerimientos o demandas impuestas a los sistemas de manejo de la calidad de las organizaciones y supervisa su cumplimiento, dando "credibilidad al sistema" (OCDE 1996: 39). Entonces, el objetivo de la aplicación de normas de calidad en el sector público tendría como objeto promover y desarrollar la eficacia en los organismos que prestan servicios a la comunidad, así como establecer una dinámica de mejora continua.

Se considera por cuanto a la calidad, hay una bifurcación que derivó en dos corrientes: una encaminada a la excelencia en las organizaciones, que tiene que ver con la administración y el desempeño; y otra a los sistemas que aseguran la calidad como la ISO, que tiene que ver con la función de calidad y el cumpli-

12 La administración de la calidad total se construyó como un sistema para medir las variaciones en los controles de producción (Deming) en la industria de la defensa en los Estados Unidos y más tarde los japoneses (Ishikawa) adoptaron y modificaron esas técnicas para constituir el centro conductor de las empresas japonesas. La administración de la calidad total se relaciona con el cambio de las organizaciones, donde la calidad y la satisfacción del cliente son las motivaciones básicas. (Pasha 2003: 48). 


\section{VICHER}

miento. Bajo esta perspectiva se cree que en las organizaciones la ISO representa el piso y los modelos de excelencia el techo, y que la organización puede necesitar ambos (Dommartin 2003: 42, 46).

\section{VARIACIONES Y CAMBIOS EN EL CONCEPTO CALIDAD}

La palabra calidad aparece por primera vez en el diccionario de la Real Academia Espańola de la Lengua, RAE, en $1729^{13}$. Para 1803 el significado era s.f. La propiedad natural de cada cosa, por la cual se distingue de las otras, qualitas, conditio. (RAE 1803: 158) y se plasmaron significados similares entre 1914 y $1950^{14}$. Es la edición de 1970 la que presenta algunas diferencias, de modo que el significado adquiere las connotaciones que hoy día nos son más familiares: propiedad o conjunto de propiedades inherentes a una cosa, que le permiten apreciarla como igual, mejor o peor que las restantes de su especie (RAE, 1970: 229). Estos mismos significados se mantienen en el diccionario de 1992 (RAE 1992: 257). Actualmente el Diccionario define la palabra como propiedad o conjunto de propiedades inherentes a algo, que permiten juzgar su valor (RAE 2001).

La Federación Española de Municipios y Provincias, ha utilizado la definición de calidad "como el conjunto de propiedades inherentes a una cosa que permiten apreciarla como igual, mejor, o peor que el resto de las de su especie" (FEMP 2006: 6), definición que el Diccionario de la Real Academia mantiene desde 1970 a 1992. Este concepto de calidad se ha considerado "tradicional" y en él suena el eco de una definición de 1729: "Usase con especialidad de esta voz en este sentido, hablando de las cosas vendibles: y así se dice comúnmente, tal género es de buena calidad, el otro no es de calidad" (RAE 1729).

Aunque el concepto de calidad ha presentado variaciones desde 1729 hasta 1950 y luego en 1970 más recientemente, de manera particular en 2006, se ha enfatizado que el concepto tradicional ha registrado otras modificaciones sustanciales que han derivado en el "moderno" concepto de calidad que la ISO 9000:2000 refirió como "conjunto de propiedades de un producto o servicio que le confieren su aptitud para satisfacer unas necesidades expresas o implícitas". Esto es, hay una

\footnotetext{
13 Calidad, s.f. Lat. Qualitas. Calidad significa también el ser y bondad de las cosas, el estado actual de estas, así en el género u especie de su constitución, como en otros requisitos y circunstancias que concurren para ser buenas o no reputadas por tales. "Usase con especialidad de esta voz en este sentido, hablando de las cosas vendibles: y así se dice comúnmente, tal género es de buena calidad, el otro no es de calidad". Se toma también por condición, requisito particular o circunstancia que se pone en algún negocio, escritura, contrato u otra cosa para su constitución y firmeza y así se dice, se concede con calidad de que ha de tener o contener tal o tal cosa.

14 Calidad. (Del laqt. qualitas, -atis.) f. Conjunto de cualidades que constituye la manera de ser de una persona o cosa. (RAE 1914: 82). Calidad. f. manera de ser de una persona o cosa. (RAE 1950: 273).
} 
variación en la forma de concebir la calidad, de modo que ya no se predica respecto de unas características intrínsecas que diferencian a un producto o servicio de otro de la misma especie (lo objetivo), sino que ahora indica la capacidad del producto o servicio para satisfacer un propósito, una necesidad o expectativa del ciudadano (lo subjetivo) (FEMP 2003: 6).

Así pues, la calidad solía referir una propiedad o conjunto de propiedades inherentes a un objeto o servicio, que permiten juzgar su valor; mientras que el concepto "moderno" la entiende como la totalidad de rasgos y características de un producto o servicio que se refiere a la habilidad de satisfacer una necesidad dada (Burgos 1994: 524).

De acuerdo con Márquez, este significado está asociado a la percepción de satisfacción de las necesidades de quien accede al producto o servicio y claramente deja ver que existe una gran subjetividad detrás del término calidad, pues dependerá de la percepción del cliente. Así, Márquez señala claramente los alcances del contenido económico del enfoque, y señala la subjetividad implícita pues se pueden tener diferentes percepciones de acuerdo con lo que para cada uno produzca satisfacción (Burgos 1994: 525, Márquez 2007: 23).

Es así que "la nueva interpretación sobre el concepto actual de calidad, se define ahora, como la satisfacción de los usuarios o la adecuación al uso" (Burgos 1994: 59). Esto explica que la esencia de la definición contemporánea de calidad es la manifestación de preferencias de los consumidores sobre los bienes y servicios que se encuentran en el mercado.

\section{LA CALIDAD PLASMADA EN MODELOS}

Los modelos de calidad se adoptaron progresivamente en la administración pública, en mucho por efecto del desarrollo y fortalecimiento de las agrupaciones privadas que crearon y fomentaron esos esquemas, y que se convirtieron en organizaciones internacionales como la Fundación Europea para la Administración de la Calidad, que fue creada en 1988 por los presidentes de 14 importantes empresas europeas y que creó el Modelo Europeo para la Excelencia Empresarial (EFQM, sigla en inglés). El objetivo de esta organización era establecer un marco europeo para el mejoramiento de la calidad en las empresas, siguiendo el modelo Malcom Baldrige de Estados Unidos y el premio Deming de Japón. Al año 2011 cuenta con 500 miembros de 55 países y 50 empresas. Desde su modelo de calidad, se desprendieron los premios a la calidad. El Primer Premio Europeo se convocó en 1992 y fue abierto a todo tipo de organizaciones. 
Otro producto derivado del Modelo Europeo para la Excelencia Empresarial EFQM, fue el Common Assessment Framework (CAF), un marco común de evaluación elaborado por los directores generales de administración pública de la Unión Europea, combinando las principales características del modelo EFQM y del modelo Speyer, así como las adaptaciones desarrolladas en varios estados miembros de la UE del modelo EFQM, para adecuarlo a las organizaciones de Administración Pública; su objetivo: gestionar la cooperación entre los socios. Al respecto se instauró un grupo de dirección integrado por los 15 Estados miembros más la Comisión, a fin de realizar intercambios internacionales y cooperación para el desarrollo de la administración pública (servicios públicos innovadores) (Ruiz 2003). En abril de 2000, los estados miembros de la Unión Europea emitieron una declaración apoyando la introducción de autoevaluaciones en todas las administraciones públicas (Dommartin 2003: 42).

Pero es importante señalar que dentro de los tratados de la Unión Europea no se contemplan los temas relacionados con las administraciones públicas; así que no se tratan en los Consejos de Ministros ni se pueden emitir disposiciones obligatorias, así que no hay una política de calidad a nivel europeo. Esto determina que la modernización de la gestión pública, se guíe por reuniones informales y convocadas a criterio del Estado que preside el Consejo. Existen, por otra parte, reuniones periódicas entre los directores generales encargados de la administración pública, para dar seguimiento al Plan a Medio Plazo, que contiene las resoluciones de los ministros. Comprende cinco grupos de trabajo, el grupo que se encarga del tema calidad es Servicios Públicos Innovadores (IPSG siglas en inglés) que tiene a su cargo el CAF (Casals 2005: 531).

Se ha enfatizado que el CAF es un modelo diseñado específicamente para las organizaciones del sector público europeo, pero "está basado en el esquema del Modelo EFQM" (Ruiz 2003: 2); y que es una herramienta para que las administraciones públicas de la UE comprendan y utilicen las técnicas de gestión de calidad en la administración pública.

Y sí, aunque efectivamente ha sido una adaptación del EFQM realizada por directores generales de administración pública de la Unión Europea, lo que se ha planteado posteriormente a los resultados obtenidos de su aplicación, alejados de las expectativas, no es otra cosa que nuevas adaptaciones del modelo a la administración pública, esto es, nuevos experimentos.

No se puede quedar sin mencionar el Modelo Iberoamericano de Excelencia en la Gestión, creado por la Fundación Iberoamericana para la Gestión de la Calidad, FUNDIBEQ, organización auto referida como independiente, que se integra con "empresas públicas, privadas y de la administración pública". Su objetivo es contribuir a "mejorar la competitividad e imagen del tejido económico y social 
de la Comunidad Iberoamericana”. Esta organización coordina el Programa y el Premio de Calidad y Excelencia de la Gestión, suscritos en la Cumbre Iberoamericana de Jefes de Estado y de Gobierno (FUNDIBEQ sin fecha).

La Carta Iberoamericana refiere que la calidad en la gestión pública es una cultura transformadora que impulsa a la administración pública a su mejora permanente para satisfacer las necesidades y expectativas de la ciudadanía con justicia, equidad, objetividad y eficiencia en el uso de los recursos públicos. Propone que las administraciones públicas iberoamericanas adopten "principios y orientaciones de referencia" en la formulación de sus políticas, planes, modelos y mecanismos para la mejora continua de la calidad de su gestión pública (CLAD 2009: 365-366).

Como es perceptible, las organizaciones dedicadas a la calidad y sus modelos, se han configurado a partir de iniciativas privadas, y quien organiza, certifica, audita y administra son organizaciones catalogadas como independientes encabezadas por ejecutivos de empresas privadas y con la participación de miembros de los gobiernos.

\section{ISO Y ADMINISTRACIÓN PÚBLICA}

Desde el ámbito jurídico se ha analizado que cuando la administración pública adopta el control de calidad, realiza un cambio que conceptualiza al ciudadano como cliente, y a la administración como a un proveedor u oferente de bienes y servicios, se presume como necesario que certifique su gestión administrativa mediante normas ISO. Así que las diferentes dependencias y entidades de la administración pública deberán contratar los servicios de las empresas certificadoras (Márquez 2007).

El concepto "moderno" de calidad que ya hemos señalado está plasmado en la norma internacional ISO sobre gestión de la calidad. En particular la Norma ISO 9000:2000 señala que calidad es la capacidad de un conjunto de características inherentes de un producto, sistema o proceso para satisfacer las necesidades explícitas e implícitas de los clientes y otras partes interesadas (Márquez 2007: 24).

Bajo este esquema, los objetivos de la organización son: reconocer las necesidades y expectativas de sus clientes y otras partes interesadas (empleados o proveedores), y satisfacerlas de manera eficaz y eficiente para mantener y mejorar el desempeño total de una organización. (FEMP 2003: 7).

Las normas de calidad se han ofrecido como los instrumentos orientadores que necesita la gestión de la calidad, pues sobre éstas se erige el sistema de gestión de la calidad de la organización (Malvicino 2001: 4). Básicamente, se considera 


\section{VICHER}

que las normas ISO constituyen un método para estandarizar las actividades de la empresa, lo que permite dar fiabilidad a los intercambios de partes y piezas entre una empresa y sus proveedores, así como mejorar la coordinación productiva ${ }^{15}$.

Los albores del siglo XX presenciaron el surgimiento de los procesos voluntarios de estandarización inventados por ingenieros que primero trabajaron en el ámbito nacional y luego en comités técnicos internacionales. Las asociaciones profesionales de ingenieros civiles, eléctricos, mecánicos e ingenieros de la industria minera constituyeron el origen del movimiento de estandarización, encarnados en cuerpos nacionales que inicialmente estuvieron financiados por asociaciones comerciales y empresas miembro. El primer director de ISO fue Howard Coonley, un industrial norteamericano (Higgins 2006: 7, 8 y 12).

De entonces a ahora notables cambios se desarrollaron pues, en las casi tres décadas pasadas, los procesos de estandarización extendieron su aplicación a problemas que tienen poco en común con aquellos que inicialmente fueron su objetivo: ensamblar una parte mecánica con otra. Incursionaron en procesos de trabajo (ISO 9000), y ámbitos como la contaminación ambiental (ISO 14000) y los derechos humanos (SA 8000) (Yates y Murphy 2006: 2).

El origen de las normas de calidad (la electrónica y en la industria militar) se ha perdido de vista. Y en general es poco señalado que, con antecedentes que datan de principios del siglo XX, en 1946 los delegados de veinticinco países crearon la Organización Internacional de Normalización (International Organization for Standarization, ISO), para facilitar la coordinación internacional y la unificación de los estándares internacionales. De entonces a nuestros días, en esta organización identificada como no gubernamental, participan miembros del sector público y privado (Márquez 2007: 28). Al año 2010 la conformaban 163 miembros, una representación por país. En el caso de México el miembro es la Dirección General de Normas de la Secretaría de Economía.

Desde su creación y hasta 1970, ISO tan sólo coordinaba a los cuerpos nacionales de estandarización, emitiendo recomendaciones sobre cómo deberían desarrollarse los estándares nacionales para ser compatibles (Higgins 2006: 7). Posteriormente su posición cambió pues empezó a publicar estándares internacionales; esto es, cambió su papel simple de organizador a rector. Además de que su posición se reforzó gracias a la Ronda de Tokio y el Acuerdo General de Tarifas de Comercio del código de estándares del GATT, que apoyaron la "autoridad" de los estándares internacionales para reducir las barreras técnicas al comercio.

\footnotetext{
15 Se denomina normalización a la elaboración de normas que reglamenten las actividades de la producción y distribución de bienes en el comercio, para beneficio del consumidor y productor (Burgos 1994: 33).
} 
El principal proceso de estándares de ISO de la serie de gerencia de calidad se publicó en 1987 (ISO 9000) como respuesta a la necesidad que planteó la intensificación del comercio y los socios comerciales a distancia, que hizo necesario establecer pruebas que demostraran que sus nuevos socios realizaban una buena gerencia (Higgins 2006: 7, 12).

Desde entonces, las normas ISO son presentadas como herramientas de saber cómo hacer las cosas relacionadas con la satisfacción del cliente y otros sujetos externos a la entidad económica, como los proveedores, o bien, sobre la obtención de utilidades y la permanencia de la empresa en el mercado. Con la certificación ${ }^{16}$, central en las normas ISO, se realiza la evaluación de los procedimientos que la empresa realiza con el objeto de asegurar la calidad en los procesos y los procedimientos, esto es, se verifica que los requisitos de la norma se cumplen. Si bien es cierto que no es ISO quien certifica sino los cuerpos que se han establecido y son acreditados por ISO.

La norma ISO 9000 se ha promovido como "un consenso internacional sobre buenas prácticas de administración” cuyo propósito es asegurar que la organización pueda entregar, repetida y sistemáticamente, productos y/o servicios que satisfacen los requisitos de calidad del cliente. La versiones que se han desarrollado son la de 1994 (ISO 9000), la del año 2000 (ISO 9000:2000) una vez que se realizó una revisión a esta norma, como resultados surgió la norma ISO 9001. La norma que está en vigencia es la ISO 9000:2008, sus cambios se refieren a la introducción de mayor claridad en los requerimientos de la norma ISO 9000:2000.

Como es visible, la auditoria de verificación ISO al convertirse en la carta profesional de las corporaciones y otras organizaciones, se vendió con gran éxito y posibilitó que a su alrededor se generara una creciente industria de consultoría sobre cómo aplicar la norma, y sobre auditoria, certificación y acreditación de certificadores. De aquí que el una vez modesto comité técnico que desarrolló las actualizaciones de ISO 9000, se convirtiera en un punto nodal del poder regulatorio trasnacional (Higgins 2006: 7).

Empero, se ha señalado que el principal resultado al que se ha llegado con las iniciativas de calidad y las certificaciones es a dar garantías de que el sistema trabaja bien, incluso cuando el desempeño sustantivo de la organización es deficiente de facto.

\footnotetext{
16 "Toda certificación es un contrato bilateral entre la empresa y la certificadora. Ambas tienen obligaciones y derechos que cumplir en función de un sello de calidad" (Malvicino 2001: 5).
} 


\section{LOS ALCANCES VELADOS DE ISO}

El análisis sobre organizaciones internacionales como ISO, ha develado que ésta, al igual que mucha de la arquitectura institucional de elaboración de normas de estandarización establecidas en el último medio siglo, forman parte del poco analizado y subteorizado campo de instituciones que han ayudado a modelar la moderna economía global (Yates y Murphy 2006: 3).

El análisis minucioso que Higgins ha realizado sobre este fenómeno lo ha llevado a concluir que en el mundo globalizado, la forma en que somos gobernados presenta una fuerte injerencia de ciertas organizaciones trasnacionales, entre las que se encuentra la ISO y la Organización Internacional de Entidades Fiscalizadoras Superiores (INTOSAI). Así que lo que no hay que perder de vista es que son cuerpos trasnacionales que no han surgido de tratados entre estados-nación. En el caso de ISO, el poder que ejerce ni es delegado de la autoridad de los estados soberanos, ni desempeña un papel financiero, por lo que su legitimidad ha emanado de fuentes alternativas, o de la pretensión de representar a una variedad de partes interesadas, incluyendo comunidades ficticias como consumidores o ambientalistas, o bien, de la producción y venta de normas en un mercado competitivo (Higgins 2006: 3, 7).

Es así que el proceso internacional de estandarización en creciente desarrollo, proveyó a ISO con la promesa de comenzar como un regulador trasnacional, y ha ido más allá desarrollando varios procesos más de estandarización, como los relativos a gerencia ambiental ISO 14000 o el estándar para la responsabilidad social ISO 26000 (Higgins 2006: 8).

Entonces, no hay que perder de vista que las organizaciones de estandarización son como las organizaciones profesionales y asociaciones de comercio de empresas individuales, y son similares a otras organizaciones voluntarias transnacionales que tienen un tipo de poder, pero que adquieren su legitimidad de una fuente esencialmente diferente de la que la obtiene su autoridad un estado soberano (Higgins 2006: 7). Su autoridad se sustenta sólo en su objetivo de búsqueda de la calidad y su legitimación no emana de acuerdos consensuados hechos entre las naciones soberanas (objeto de sus certificaciones).

Como es patente, las organizaciones de esta índole están asumiendo funciones de regulación, de manera creciente, y esto no es sino un reflejo de la desregulación que se está verificando por cuanto a los campos de actividad que está cediendo o abandonando el Estado y su administración pública, pues al tiempo que dejan de realizar estas regulaciones, las asume otro sector cuya autoridad no se desprende de la autoridad soberana que tiene el Estado-nación. 


\section{ADOPCIÓN Y APLICACIÓN DE ESQUEMAS DE CALIDAD EN MÉXICO}

Dado que forman parte de las reformas neogerenciales, las normas e iniciativas de calidad pueden rastrarse en los planes y acciones de gobierno de las administraciones de Carlos Salinas de Gortari (1988-1994), Ernesto Zedillo (1994-2000), y principalmente en la de Vicente Fox (2000-2006), donde cobra gran auge el modelo de calidad y el respectivo premio, lo mismo que las certificaciones ISO dentro del gobierno.

En el caso particular del gobierno de Salinas de Gortari, en 1992, se expidió la Ley Federal de Metrología que se divide en dos secciones, la primera trata sobre metrología y la segunda sobre normalización (normas de calidad), certificaciones, verificaciones y acreditamiento (Márquez 2007: 43).

Los aspectos relacionados con la normalización, la certificación, el acreditamiento y la verificación se plasmaron en la Ley Federal sobre Metrología y Normalización. Esta Ley señala tener como objetivo fomentar la transparencia y eficiencia en la elaboración y aplicación de normas oficiales mexicanas, instituir la Comisión Nacional de Normalización ${ }^{17}$, establecer un procedimiento uniforme para la elaboración de normas oficiales por las dependencias de la Administración Pública Federal, coordinar actividades de normalización, certificación y verificación de las dependencias de la Administración Pública Federal, establecer el Sistema nacional de Acreditamiento de Organismos de Normatización y Certificación.

En la Ley Federal sobre Metrología y Normalización la certificación se define como el procedimiento por el cual se asegura que un producto, proceso, sistema o servicio se ajusta a las normas o lineamientos o recomendaciones de organismos dedicados a la normalización, sean nacionales o internacionales. Particularmente es el artículo 51-A, fracc. II donde se señala que las normas internacionales pueden servir de base a las normas mexicanas, y éstas últimas pueden transformarse en normas oficiales mexicanas. Es de esta manera que las normas técnicas expedidas por organismos como ISO pueden obtener carácter de obligatorias. El mismo artículo también dispone que se debe cumplir con las normas oficiales (Márquez 2007: 44-45).

Pero, como lo pone de manifiesto Márquez, dotar de mayor calidad a la administración pública suena muy atractivo puesto que ello puede ayudar a mejorar

17 La Comisión Nacional de Normalización (CNN) es el órgano de coordinación de la política de normalización a nivel nacional y está integrada por 43 miembros entre dependencias y entidades de la administración pública federal, cámaras, organismos nacionales de normalización y asociaciones, que se encuentran vinculados al ámbito de la normalización (Secretaría de Economía sin fecha). 


\section{VICHER}

la calidad de los servicios, lo que resultaría en beneficio de los ciudadanos. No obstante, en la Ley se dispone que se deben cumplir las normas oficiales mexicanas y esto, dado que para su elaboración tienen como base las normas internacionales, esto genera una obligatoriedad que da lugar también a que se hagan obligatorias para la administración pública las normas emitidas por organismos internacionales como ISO "se podría concluir que las dependencias y entidades de la administración pública están obligadas a velar por la calidad de sus procesos y a certificarlos" (Márquez 2007: 59).

Más tarde, dentro de las reformas neogerenciales, la administración de Vicente Fox asumió que:

(...) la política de calidad del Gobierno Federal tiene por objetivo lograr un gobierno de clase mundial, innovador y con una sólida cultura de calidad total, capaz de proyectar una imagen confiable y transparente. Para ello, ha sido necesario reemplazar los esquemas tradicionales de la gestión pública por los más avanzados sistemas administrativos y tecnológicos; evaluar su gestión con base en estándares de competitividad, promover la dignificación y eficacia del servicio público, rediseñar sus procesos y servicios, y dirigir su quehacer hacia el cumplimiento de las expectativas y necesidades de los ciudadanos (Presidencia de la República 2003: 379).

Este punto de vista se reafirma al final de esta administración, pues el informe de gobierno de 2006, en su apartado "Gobierno de Calidad", afirma que siguiendo las tendencias mundiales de gestión pública se han incorporando los principios de la calidad total y la certificación con estándares internacionales para satisfacer las necesidades de la sociedad mexicana (Presidencia de la República 2005: 403).

En México se dio por sentado que los sistemas de calidad pueden organizar los recursos para lograr los objetivos de cualquier organización, si se establecen, siguen y mantienen reglas e infraestructura que permitan producir los resultados deseados. También, que su uso generalizado estaría en función de contar con reconocimiento universal usando como plataforma normas técnicas como ISO.

De hecho, se ha encontrado que en México la intervención del Estado se verificó con gran fuerza en la elaboración de normas y que hubo una activa participación en actividades de normalización internacional, lo cual vinculó cercanamente a las autoridades administrativas de México con ISO, y esto, como lo ha señalado Márquez, es una situación que "atenta contra la pretendida democratización en la elaboración de normas". Además de que "las normas ISO transforman la relación entre la administración y el gobernado, puesto que éste se transforma de admi- 
nistrado en 'cliente", sin que se consideren las implicaciones sobre los derechos ciudadanos (Márquez 2007: 25, 62).

Es evidente que la mezcla y asimilación entre lo público y lo privado ha llevado a que una serie de reglas utilizadas para verificar la calidad de organizaciones privadas, de complejidad menor, objetivos limitados, dedicados a producir mercancías se hayan utilizado para abordar la complejidad de una organización como la administración pública que fundamentalmente tiene que ver con relaciones de poder, relaciones políticas, económicas y sociales muy complejas.

En México han participado cinco representaciones de organismos extranjeros, los cuales están autorizados para otorgar certificaciones por medio de su casa matriz. Pero la capacidad de acreditación que tienen les es otorgada por el organismo oficial del país de origen. Estos organismos no cuentan con el reconocimiento del gobierno mexicano, pero se justifica su operación en el territorio nacional, porque la certificación que proporcionan tiene aceptación internacional; en este caso se encuentran, AQSR Internacional, Inc. (AQSR); Asociación Alemana para la Certificación de Sistemas de Calidad (DQS); Enviroment and Quality Assuranced Internacional Systems (EQAICC); Intertek Testing Services (ITS), y KPMG Quality Registrar Inc. (KPMG) (Conacyt 2006: 220), British Standard Institutions BEI, que ha efectuado auditorías externas a la Auditoría Superior de la Federación de México (ASF sin fecha), entre otros.

A su vez, existen 34 que organismos privados de certificación de sistemas de gestión de la calidad, cada uno abarca una gran cantidad de sectores (alimenticios, químicos, metales, maquinaria y equipo, hoteles, restaurantes, educación, construcción, transporte), de los cuales, 31 también están acreditados para certificar de Sistemas de Gestión de la Calidad de la Administración Pública (Secretaría de Economía 2008).

La Secretaría de Economía señala que "los organismos de certificación, son personas morales que tienen por objeto realizar tareas de certificación, esto es, evaluar que un producto, proceso, sistema o servicio se ajuste a las normas, lineamientos o reconocimientos de organismos dedicados a la normalización nacionales o internacionales. Y declara que su estatus es de "tercero independiente", al referirlas como "instituciones de tercera parte" en cuya estructura técnica funcional participan los sectores: productor, distribuidor, comercializador, prestador de servicios, consumidor, colegios de profesionales, instituciones de educación superior y científicas (Secretaría de Economía 2008). 


\section{CALIDAD Y NORMAS ISO DENTRO DEL GOBIERNO MEXICANO}

En México la aplicación de estos planteamientos dentro de la administración pública se rastrean desde el año 1997, de lo cual es prueba fehaciente la inclusión de disposiciones oficiales mexicanas con relación a la aplicación de normas de calidad (Márquez 2007: 42, 43).

Aunque con estos antecedentes de 1997, es en la administración de Vicente Fox cuando cobra gran auge el movimiento de la calidad, lo cual se ve reflejado incluso en la elaboración del denominado Modelo Estratégico para la Innovación y la Calidad Gubernamental, en 2001. Existe una tendencia muy proclive a las certificaciones ISO. Resalta también la creación del Premio Nacional de Calidad, dirigido a fabricantes y prestadores de servicios, públicos o privados, en calidad total en los procesos industriales, productos y servicios.

Como ejes del mejoramiento del gobierno se incrustaron en el Plan Nacional de Desarrollo 2001-2006 donde se señaló a la calidad total como el medio para mejorar y optimizar el desempeño del gobierno. Desde entonces el tema se ha internalizado. La Ley Orgánica de la Administración Pública, en su artículo 34, fracc. XIII, asigna a la Secretaría de Economía la competencia de establecer y vigilar las normas de calidad.

Entre las estrategias que sugirió el gobierno de Vicente Fox para impulsar la innovación y la calidad en la Administración Pública Federal se contempló la administración por calidad pues se argumentaba que la evolución de los sistemas de calidad en el mundo -desde el control de calidad, los sistemas de aseguramiento de la calidad y el establecimiento de las normas ISO 9000-, había avanzado en el mejoramiento de los modelos y las prácticas de gestión y management. También se aseguraba que se había comprobado que el enfoque de calidad total de la gerencia y la administración conseguía mejores resultados en cuanto a la satisfacción y confianza de los clientes (Muñoz 2001: 21).

Este gobierno renovó la certificación ISO 9000 en 429 centros de trabajo del Gobierno que la obtuvieron en el año 2000. Reportó que en 2001 se certificaron 110 centros más (539), en 2002 sumaban 684, aunque en el año 2003, 869; en 2004 se reportaron 1.426; y a marzo de 2005, 1.676 (Presidencia de la República 2005: 403). En el último informe de gobierno de esta administración (2006), primer trimestre se reportaron 2.351 centros de trabajo certificados con estándares internacionales ISO 9001 que involucraron 1.800 procesos. No obstante, se informa que se está optando por certificados multisitio que consiste en un único certificado ISO 9001:2000 para las instituciones públicas que cuentan con diversos centros de trabajo (aplican el mismo Sistema de Gestión de la Calidad para todas sus áreas), a fin de ahorrar recursos (Presidencia de la República 2006: 401). 
En 2001 se estableció el Consejo Nacional de Organismos Estatales por la Calidad (CONOREC), como organismo nacional para agrupar a "las instituciones estatales dedicadas a impulsar, promover y desarrollar la cultura de calidad total en sus entidades" (Presidencia de la República 2004: 5).

También durante 2001 se implantó un modelo interno de calidad, denominado Modelo de Calidad INTRAGOB, dirigido a satisfacer las expectativas y necesidades de los ciudadanos sobre los productos y servicios que proporciona y para consolidar la cultura de calidad. Las directrices del Modelo de Calidad INTRAGOB se definieron como: satisfacción del cliente, liderazgo, desarrollo de funcionarios y gestión de capital intelectual, administración de la información y de la tecnología, planeación, gestión y mejora de los procesos, impacto, y resultados.

Desde luego se estableció el Premio INTRAGOB, como un distintivo a los mayores avances en Calidad Total dentro de la APF. Los ingenieros que elaboraron el Modelo INTRAGOB, afirmaron que constituía una nueva filosofía de gestión de la administración pública federal para satisfacer las expectativas de los clientes y ciudadanos, y mejorar los resultados. En el modelo se integraron mediciones, a fin de determinar el grado de satisfacción de los clientes, ciudadanos y servidores públicos, para mejorar los procesos y sus resultados, identificando los puntos de control y los factores críticos de éxito (Sánchez, Rincón y González 2005).

A partir de noviembre de 2004, se inició el establecimiento de la Carta Compromiso al Ciudadano, entendida como un sistema de gestión de calidad, con estándares que las entidades se comprometen a cumplir, un documento público donde se plasmaría toda la información necesaria para que los ciudadanos solicitaran servicios y realizaran sus trámites. Estas cartas, dado que se percibieron como un medio para conocer las necesidades y expectativas de los ciudadanos, se visualizaron como integrables a otros sistemas de gestión de la calidad como ISO.

$\mathrm{Al}$ año 2005, se reportaba la publicación de 85 cartas compromiso al ciudadano y trabajos avanzados en otras 150. (Presidencia de la Republica 2005: 403, 404). Para 2006, se reportaba lo que parece ser un gran triunfo en este rubro pues se contaban ya 260 cartas de compromiso al ciudadano de 64 dependencias y entidades de la APF, que se calificaron de exitosas al obtener resultados en el cumplimiento de estándares de 99,8\% a nivel interno y 95.9\% en el externo (Presidencia de la Republica 2005: 401).

Durante esta administración también se articuló una red de calidad integrada por los representantes del más alto nivel de todas las secretarías de estado y de las entidades más importantes del gobierno. La Red de Calidad del Gobierno Federal, siguiendo el Plan de Calidad del Gobierno Federal buscaba lograr un gobierno certificado, en su totalidad, en términos de ISO 9000:2000 (IIE 2002: 149). 
En 2005, se presentó el Modelo Nacional para la Calidad Total, donde se plasman los lineamientos para el premio nacional de calidad. En el documento se señala que su intención es impulsar la competitividad de las organizaciones mexicanas de cualquier giro o tamaño, para proyectarlas a ser de clase mundial (Consejo Técnico del Premio Nacional de Calidad 2005: 3).

La capacitación de los funcionarios públicos se diseñó en función de fortalecer la cultura de calidad a nivel nacional. En la mayoría de las organizaciones de la APF se elaboró un programa de capacitación para que los funcionarios mejoraran sus habilidades de servicio en forma continua. También se creó el Diplomado de Calidad Gubernamental para capacitar a los coordinadores de calidad en la APF y para formar evaluadores del Modelo de Calidad INTRAGOB.

Al iniciar el año 2006, existían treinta organismos de certificación en el país, reconocidos por la Dirección General de Normas (DGN) de la Secretaría de Economía (SE); y que fueron autorizados por la Entidad Mexicana de Acreditación (EMA, creada en 1998) que es el órgano de gestión privada, profesional responsable de acreditar la operación de los organismos de certificación reconocidos de manera oficial en el país. Tiene como objeto operar como entidad de acreditación en los términos de la Ley Federal sobre Metrología y Normalización. Esta facultad le fue otorgada por la Secretaría de Comercio y Fomento Industrial, hoy Secretaría de Economía (Entidad Mexicana de Acreditación 2006: 6, 7).

De acuerdo con el Diario Oficial de la Federación, publicado el 15 de enero de 1999, la Entidad Mexicana de Acreditación, A. C. (EMA), obtuvo facultades para realizar la función de acreditación de organismos de certificación, laboratorios de prueba y calibración y unidades de verificación ${ }^{18}$ (DOF 1999: 1). Los organismos de certificación acreditados por la EMA cuentan con la capacidad para emitir certificados a favor de las empresas en las normas ISO-9001:2000, ISO-14001 y otras que integran el grupo de normas ISO (Conacyt 2006: 218-220).

En el año 2006, cuando inicia la administración de Felipe Calderón, se da un viraje por cuanto al lugar que ocuparán la calidad, las ISOs y el Modelo de Calidad

\footnotetext{
18 La base legal de dicha facultad se desprendió de los artículos 90 de la Constitución Política de los Estados Unidos Mexicanos, 16 y 34 de la Ley Orgánica de la Administración Pública Federal; 39 fracción IX, 70-A, 70-B y 70-C de la Ley Federal sobre Metrología y Normalización; 1o., 2o. y 4o. del Reglamento Interior de la Secretaría de Comercio y Fomento Industrial. En particular, el artículo 39, fracción IX, 70-A, 70-B y 70-C de la Ley Federal sobre Metrología y Normalización reza lo siguiente: Artículo 39, fracción 10. Corresponde a la Secretaría [también], coordinar y dirigir los comités y actividades internacionales de normalización y demás afines a que se refiere esta Ley. Artículo 70-A. Para operar como entidad de acreditación se requiere la autorización de la Secretaria, previa opinión favorable de la mayoría de los miembros de la Comisión Nacional de Normalización a que se refiere la fracción I del artículo 59. El artículo 70-B indica las obligaciones de la o las entidades de acreditación (Cámara de Diputados 2009).
} 
INTRAGOB dentro de la administración pública. Mientras Vicente Fox tenía un apartado del Plan Nacional de Desarrollo dedicado al punto, Felipe Calderón en su el Plan Nacional de Desarrollo 2007-2012 (Gobierno de los Estados Unidos Mexicanos 2007: 25) sólo refiere los servicios de calidad en general, o con relación a la economía, servicios de salud o programas contra la pobreza. Pero no existe en el plan lugar para la calidad gestión pública como tal; contiene un apartado que se refiere a la eficacia y eficiencia gubernamental (Gobierno de los Estados Unidos Mexicanos 2007: 285-292), pero lo que se propone para lograrlas es nuevo tipo de gestión pública para resultados.

Pareciera que en el Plan Nacional de Desarrollo 2007-2012 hubo omisiones sobre el mejoramiento de la gestión pública, así que en 2008 se publica el Programa Especial de Mejora de la Gestión en la Administración Pública Federal 2008-2012. En el Programa se señala que pese al aumento de recursos a la administración pública, no se ha logrado una mejora permanente en el acceso a bienes y servicios de calidad (Gobierno Federal 2008: 11).

En el segundo informe de ejecución se retoman los avances y aplicación de las Cartas Compromiso al Ciudadano y para el año 2007 se reportaron 326 en 64 instituciones (Presidencia de la República 2007: 41). Y también se menciona el Programa de Mejoramiento de la Gestión (PMG 2008-2012), cuya fecha de publicación no corresponde a 2007, situación de la que da cuenta el Boletín de la Cámara de Diputados del 5 de septiembre de 2008, en el que se informa que existe un esbozo del PMG, pero que no se ha presentado formalmente ni se ha publicado en el Diario Oficial de la Federación (DOF) (Cámara de Diputados 2008: 1-2). Es el 10 del mismo año cuando se publica en el DOF el Programa Especial de Mejora de la Gestión en la Administración Pública Federal 2008-2012.

Aunque el programa no trata específicamente de ISO, señala que se han impulsado los modelos de calidad como la Certificación ISO-9000 y suscribe que entre sus objetivos está el reducir la desigualdad en el grado de desarrollo de las organizaciones públicas mediante la mejora de áreas gerenciales comunes, gracias a la estandarización de mejores prácticas (Gobierno Federal 2008: 17, 19). Entre los indicadores y metas que se establecen en el programa encontramos los siguientes relativos a calidad: 
Tabla 1: Indicadores y metas del PMG en calidad

\begin{tabular}{|l|l|l|l|}
\hline Nombre del indicador & Unidad de medida & $\begin{array}{l}\text { Situa- } \\
\text { ción } \\
2006\end{array}$ & $\begin{array}{l}\text { Meta } \\
2012\end{array}$ \\
\hline $\begin{array}{l}\text { Trámites y servicios con es- } \\
\text { tándares de calidad }\end{array}$ & $\begin{array}{l}\text { Porcenjate de trámites y servicios } \\
\text { con estándares en la APF }\end{array}$ & $6,9 \%$ & $25 \%$ \\
\hline $\begin{array}{l}\text { Percepción ciudadana de la } \\
\text { calidad de trámites y servi- } \\
\text { cios de mayor impacto }\end{array}$ & $\begin{array}{l}\text { Porcentaje de satisfacción de usua- } \\
\text { rios respecto a los 100 trámites y } \\
\text { servicios de mayor impacto en la } \\
\text { APF }\end{array}$ & $90 \%$ \\
\hline
\end{tabular}

*N.D. Información no disponible.

Fuente: Gobierno Federal (2008: 31).

Entre las estrategias y líneas de acción que se plantearon sobre calidad están la mejora en trámites y prestación de servicios para brindarlos oportunamente y con calidad, y el establecimiento de estándares de servicio.

En el Tercer Informe de Ejecución tampoco se hace alusión a las cartas compromiso al ciudadano ni a las certificaciones ISO (Presidencia de la República 2009: 66). Mientras, en el Cuarto Informe de Ejecución se abrogan las cartas de compromiso al ciudadano. El cuarto informe de ejecución, en el apartado sobre "Reducir los trámites burocráticos con la finalidad de abatir la discrecionalidad señala que por cuanto a las Cartas Compromiso al Ciudadano:

(...) en el marco del Programa Especial de Mejora de la Gestión Pública (PMG) y de la estrategia de Regulación Base Cero, del 12 de abril de 2010 en el Diario Oficial de la Federación, se emitió el Acuerdo por el que se abrogan diversas disposiciones aplicables en la SFP, destacando la normatividad que sustentaba el instrumento de las CCC y los CIS. A las instituciones que solicitaron dar de baja sus CCC, se les responsabilizó tanto de la medición de la percepción de los usuarios, como la mejora continua de los trámites y servicios (Presidencia de la República 2010: 66).

Aunque la exaltación por las normas ISO ha perdido vigor, en México se continúan visualizando como un medio muy útil para establecer sistemas de calidad, como es el caso de la Secretaria de la Función Pública, que habiendo iniciado la certificación de procesos en 2001, cada seis meses realiza auditorías de seguimiento. En 2006 instaló formalmente el Comité de Calidad y resalta que en 2008 certificaron 6 procesos integrales que se re-certificaron en 2009 (Merino 2009: 175-176). Y en 2009, re-certificó todos los procesos de su Sistema de Gestión de la Calidad bajo la norma ISO 9001:2008 (ASF sin fecha). Actualmente, su Sis- 
tema de Gestión de Calidad tiene la certificación ISO 9001:2008. La institución ha expresado que la adoptó porque permite garantizar la excelencia institucional, establecer una cultura de la calidad, y tienen un aval de que cumplen los requisitos establecidos en el estándar (ASF sin fecha).

Incluso la certificación ISO se ha constituido como un importante objetivo de gobierno, por ejemplo, en el estado de Chiapas cuya Dirección de Adquisiciones de la Secretaría de Hacienda, en su objetivo 12 estableció mantener la certificación ISO 9001:2000 del Sistema de Dirección por Calidad de Adquisiciones, en congruencia con el Plan de Desarrollo Chiapas Solidario 2007-2012 (Secretaría de Hacienda de Chiapas sin fecha).

\section{CERTIFICACIONES EN MÉXICO}

Para el año 2005 se registró que de las certificaciones efectuadas 60\% correspondía al sector privado y el $40 \%$ al sector público, donde sobresalen las universidades tecnológicas e institutos tecnológicos que se trabajaron para establecer un sistema de gestión de calidad. En este sector, las dependencias que más certificaciones registraron (21.3\%) fueron la Comisión Federal de Electricidad y PEMEX, mientras que la Secretaría de Educación Pública el 5.2\% y la Secretaría de Economía el 3.5\%. Otras instituciones públicas promovieron la certificación, con el objeto de crear una infraestructura organizacional y un sistema de gestión pública enfocado a administrar la calidad dentro de cada institución y orientada a satisfacer al público usuario de los servicios. Tal es el caso del gobierno del Estado de México que ha promovido el sistema de gestión de la calidad y que registró un 3.2\% de certificaciones en el sector público (Conacyt 2006: 225).

Dada la difusión y promoción de ISO y de las certificaciones como garantía de calidad, se llegó a considerar que la sociedad estaba inmersa en una revolución de la calidad, en la que las empresas y organizaciones para su éxito, tendrían que contar con una moderna cultura empresarial y de negocios.

También las entidades del gobierno de las esferas federal, estatal y municipal han desempeńado un papel importante, por lo que se creyó necesario el incremento del número de certificaciones. Asimismo, se consideró urgente elevar la producción de recursos humanos de alto nivel en las áreas de ingeniería relacionadas con el quehacer de la producción y su administración moderna y eficiente para contribuir al logro de una mayor "cultura de la calidad" a fin de promover mejores empresas privadas, y en el gobierno instituciones eficientes, eficaces, transparentes y de calidad en la prestación de sus servicios (Conacyt 2006: 228). 
Empero, las certificaciones de calidad efectuadas a partir de las normas internacionales no son sino uno más de los instrumentos que se han desplegado para meter al mercado dentro del Estado. Ahora quien define si los gobiernos efectúan bien o mal su trabajo son los terceros externos, que son principalmente empresas privadas con intereses particulares, aunque se identifiquen como organizaciones independientes e imparciales. En la mayoría de ellas se encuentra el vínculo directo hacia las empresas con las que se contrata la certificación y también hacia las empresas que asesoran para la certificación, o dicho de manera más clara, hacia quien podrá hacer contratos y negocios para avalar que en la administración pública se haga bien ¡lo que de antemano debería estar bien hecho!

Es así que el mercado en las normas invocó la rápida expansión del mercado en auditoria, certificación y acreditación basada en sus normas (Higgins 2006: 3, 4). Así pues, las certificaciones también constituyen un excelente negocio que los privados están haciendo a costa del presupuesto público, pero sobre todo de sus ciudadanos, pues en realidad no han contribuido a un mejoramiento sustancial, e incluso se estuvo experimentando con las formas de certificar dentro de las diferentes oficinas públicas.

Veamos algunos ejemplos que respalden lo que acabamos de aseverar. Como revisaremos a continuación, un proceso de certificación es costoso, implica recabar una gran cantidad de documentos, disponer de personal que se dedicará exclusivamente a dicha tarea, y no sólo esto sino que también, para obtener la certificación se tendrá que hacer otro contrato en la parte relativa a la asesoría para la instrumentación del sistema de gestión de la calidad.

Dado que el tema perdió fuerza en la administración vigente, retomaremos el último dato de 2006, de la administración de Vicente Fox, que reportaba 2.351 centros de trabajo certificados con estándares internacionales ISO 9001, usaremos algunos datos del cuadro que ofrecemos a continuación, donde se plasman los costos implicados en la certificación de dos instituciones mexicanas.

Nos centraremos sólo en las que se refiere a la asesoría para la implantación e instrumentación del sistema de calidad (33.173,08 USD) y en el costo de los servicios de certificación de sistema de gestión de la calidad (5.750 USD), conservando los precios de 2003. Si de manera muy conservadora asumimos que cada centro de trabajo de los 2.351 sólo hace estos pagos una vez, tendríamos una suma de 91'508'161.08 USD. Ahora bien, si sólo consideramos que cada centro de trabajo tiene que contratar también servicios de auditorías especializadas o auditorias de seguimiento cada seis meses, esto resulta en un gasto realmente impresionante. 
Origen y Efectos de las Normas de Calidad en la Administración Pública

Tabla 2: Secretaría de Seguridad Pública, contrataciones ISO 2003 y 2005

\begin{tabular}{|c|c|c|c|}
\hline Contrato & Empresa & Vigencia & Costo* \\
\hline $\begin{array}{l}\text { Servicio de Auditoría especializada para } \\
\text { mantener la vigencia de la certificación } \\
\text { bajo las normas NMX-CC-9001-IM- } \\
\text { NC:2000 e ISO 9001:2000 }\end{array}$ & $\begin{array}{l}\text { International } \\
\text { Certification } \\
\text { of Quality } \\
\text { Systems S.C. }\end{array}$ & $\begin{array}{l}23 / 09 / 2003 \\
30 / 09 / 2003\end{array}$ & $5.741,15$ \\
\hline $\begin{array}{l}\text { Servicios de certificación de sistemas de } \\
\text { gestión de la calidad instaurados en pro- } \\
\text { cesos sustantivos de la Secretaría durante } \\
2003 \text { bajo los requisitos de la Norma In- } \\
\text { ternacional ISO 9001:2000 }\end{array}$ & $\begin{array}{l}\text { A m e r i c a n } \\
\text { Trust Regis- } \\
\text { teer S.C. }\end{array}$ & N.D.* & $90 \%$ \\
\hline $\begin{array}{l}{ }^{* *} \text { Servicios de capacitación y asesoría es- } \\
\text { pecializada para la implantación e ins- } \\
\text { trumentación del sistema de gestión de } \\
\text { la calidad en procesos sustantivos en los } \\
\text { órganos administrativos desconcentrados, } \\
\text { para obtener su certificación en las nor- } \\
\text { mas NMX-CC-9001-IMNC:2000 e ISO } \\
9001: 200\end{array}$ & $\begin{array}{l}\text { Instalaciones } \\
\text { en productivi- } \\
\text { dad S.C. }\end{array}$ & $\begin{array}{l}1 / 12 / 2003 \\
31 / 12 / 2003\end{array}$ & $33.173,08$ \\
\hline $\begin{array}{l}\text { Servicios de capacitación y asesoría espe- } \\
\text { cializada para la implantación e instru- } \\
\text { mentación del sistema de gestión de la } \\
\text { calidad en procesos sustantivos para obte- } \\
\text { ner certificación en las normas NMX-CC- } \\
\text { 9001-IMNC: } 2000 \text { e ISO 9001:2000 }\end{array}$ & $\begin{array}{l}\text { Centro de So- } \\
\text { luciones de } \\
\text { Calidad }\end{array}$ & $\begin{array}{l}25 / 09 / 2003 \\
31 / 12 / 2003\end{array}$ & $30.607,69$ \\
\hline $\begin{array}{l}\text { Servicios de capacitación y asesoría espe- } \\
\text { cializada para la implantación e instru- } \\
\text { mentación del sistema de gestión de la } \\
\text { calidad en procesos sustantivos para obte- } \\
\text { ner su certificación con base en las nor- } \\
\text { mas NMX-CC-9001-IMNC: } 2000 \text { e ISO } \\
\text { 9001:2000 (recursos humanos) }\end{array}$ & $\begin{array}{l}\text { Instalaciones } \\
\text { en productivi- } \\
\text { dad S.C. }\end{array}$ & $\begin{array}{l}25 / 09 / 2003 \\
31 / 12 / 2003\end{array}$ & $13.932,69$ \\
\hline \multicolumn{3}{|l|}{ Total (Septiembre-Diciembre 2003) } & $82.204,61$ \\
\hline $\begin{array}{l}\text { Servicios especializados para realizar la } \\
\text { preauditoría y auditoría de certificación } \\
\text { los sistemas de gestión de la calidad en } \\
\text { procesos sustantivos de la SSP con base en } \\
\text { las normas NMX-CC-9001-IMNC:2000 } \\
\text { o su equivalente nacional la NMX-CC- } \\
9001 \text {-IMNC-2001. }\end{array}$ & $\begin{array}{l}\text { Centro de So- } \\
\text { luciones de } \\
\text { Calidad }\end{array}$ & $\begin{array}{l}01 / 12 / 2005 \\
20 / 12 / 2005\end{array}$ & $6.926,54$ \\
\hline
\end{tabular}

Fuente: Elaboración propia con base en: Secretaría de Seguridad Pública, Portal de obligaciones de transparencia, http://www.portaltransparencia.gob.mx/pot/contrataciones.

*Dólares cotización correspondiente al año 2011.

**Órganos administrativos desconcentrados. 
Como se observa, las empresas que contrató la Secretaría de Seguridad Pública mexicana para la auditoria especializada para mantener la certificación y la certificación de sistemas de calidad, fueron International Quality Certifications S.A. de C.V. y American Trust Register S.C. Pero, como se puede apreciar, se gastó mucho más en la asesoría contratada a las otras dos empresas (Instalaciones en productividad S.C. y Centro de Soluciones de Calidad) para ayudar a los servidores públicos a preparar la documentación para realizar el proceso de la certificación. Como se puede observar, los montos son altos y por muy pocos meses.

Tabla 3: Instituto de Seguridad y Servicios Sociales de los Trabajadores del Estado, contrato ISO 2007

\begin{tabular}{|l|l|l|l|}
\hline Contrato & Empresa & Vigencia & Costo* \\
\hline $\begin{array}{l}\text { Servicios de certificación de Auditorias } \\
\text { y Seguimiento a los Sistemas de Gestión }\end{array}$ & BVQI MEXI- & 16/07/2007 & $3.550,30$ \\
Ce la Calidad, con base en la Norma S.A. & 20/12/2007 & \\
ISO9001:2000 & DE C.V. & & \\
\hline
\end{tabular}

Fuente: Elaboración propia con base en: Instituto de Seguridad y Servicios Sociales de los Trabajadores del Estado, ISSSTE, Portal de Obligaciones de Transparencia, http://www. portaltransparencia.gob.mx/pot/contrataciones.

*Dólares cotización correspondiente al año 2011.

Tabla 4: Auditoria Superior de la Federación, contrataciones ISO Abril-Junio 2007

\begin{tabular}{|l|l|l|l|}
\hline Contrato & Empresa & Vigencia & Costo* $^{*}$ \\
\hline $\begin{array}{l}\text { Actualización de la Norma ISO } \\
9001: 2008\end{array}$ & $\begin{array}{l}\text { BSI Manage- } \\
\text { ment Systems } \\
\text { México, S. de } \\
\text { R.L. de C.V. }\end{array}$ & $\begin{array}{l}14 \text { al 25 } \\
\text { de abril de } \\
2009\end{array}$ & 6.900 \\
\hline $\begin{array}{l}\text { Contratación de servicios de auditoría de } \\
\text { mantenimiento al certificado número FS } \\
\text { 509820 bajo la Norma ISO 9001:2000 }\end{array}$ & $\begin{array}{l}\text { BSI Manage- } \\
\text { ment Systems } \\
\text { México, S. de } \\
\text { R.L. de C.V. }\end{array}$ & $\begin{array}{l}13 \text { de abril } \\
\text { al 31 de } \\
\text { octubre de } \\
2009\end{array}$ & $18.576,92$ \\
\hline $\begin{array}{l}\text { Contratación de un auditor interno ISO } \\
9001: 2008 \text { Certificado }\end{array}$ & $\begin{array}{l}\text { Bureau Veritas } \\
\text { Mexicana, S.A. } \\
\text { de C.V. }\end{array}$ & $\begin{array}{l}29 \text { de junio } \\
\text { al 16 de ju- } \\
\text { lio de 2009 }\end{array}$ & $7.076,92$ \\
\hline
\end{tabular}

Fuente: Elaboración propia con base en Auditoria Superior de la Federación (2009).

*Dólares cotización correspondiente al año 2011.

Otras cuestiones que se han desprendido de la experiencia de la implantación de normas ISO, es que las estructuras dentro del gobierno se han agrandado. Este es particularmente el caso de la Secretaría de Educación Pública donde, dentro de la Dirección General de Acreditación, Incorporación y Revalidación, se creó una Dirección de Acreditación y Certificación, una Coordinación de Planeación y Gestión de la Calidad, una Subdirección de Control y Evaluación de la Acredi- 
tación y Certificación, una Subdirección de Diseño y Desarrollo de la Acreditación y la Certificación; un Departamento de Programación, Operación, Análisis y Evaluación de la Acreditación y Certificación; un Departamento de Estudios para la Evaluación de la Acreditación y Certificación; y un Departamento de Estudios para la Acreditación y Certificación de la Educación Media Superior, Superior y Formación para el Trabajo.

Si bien los costos de la certificación ISO pueden variar y las estructuras que se han establecido dentro de la administración pública pueden ser menores, en la mayoría destaca el establecimiento de comités de calidad.

\section{CONCLUSIONES}

La reconfiguración de las relaciones de poder en la era neoliberal implicó cambios radicales en las funciones y objetivos de actores como las organizaciones públicas internacionales FMI, BM, OCDE, y trajo a escena a otros tantos como Organización Internacional de Estandarización ISO, y otros cuerpos de estandarización que han llegado recientemente al escenario normativo.

Como lo ha señalado Higgins el neoliberalismo fue la fuerza que impulsó el interés en organizaciones internacionales como ISO, así que los gobiernos neoliberales han reemplazado la regulación económica directa con varias formas de autoregulación basadas en requerimientos formales de presentación de informes. Aquí se ha observado una tendencia hacia el reemplazo de las leyes "duras" de los estados soberanos con los "suaves" estándares, normas y reglas de los cuerpos trasnacionales, que se adapta al patrón ventriloquista del gobierno neoliberal a distancia que se manifiesta con mayor fuerza desde que el resultado favorable de una auditoria constituye el sello de calidad de la legitimación y de una organización comercial(izada).

En particular, la influencia y papel real de organizaciones estandarizadoras como ISO, puede distinguirse cuando se cae en la cuenta de que la responsabilidad cambió fuera de los creadores de normas hacia los seguidores de las mismas. Esto es, los estados-nación renunciaron o abandonaron su responsabilidad en la tarea de crear este tipo de regulaciones y normas, y cedieron esa facultad a quienes eran los seguidores o sujetos de las mismas (cuerpos de ingenieros, empresarios, gerentes, industriales, entre otros).

En la administración pública la noción de calidad que se ha aplicado desde 1980 tiene su fuente en la nueva gerencia pública que la OCDE impulsó con gran fuerza. La nueva gerencia pública contempló los modelos de calidad y promovió las ventajas de la certificación por un "tercero externo y neutral", como 


\section{VICHER}

medio para dar credibilidad a la administración pública. Asimismo, la noción de calidad que adoptó la OCDE, presenta dos corrientes, una dirigida la excelencia en las organizaciones y otra a los sistemas que aseguran la calidad como la ISO. La primera se ha desarrollado a partir de los modelos de calidad y de las Cartas Compromiso a los Ciudadanos.

Empero, como buen elemento de la nueva gerencia pública, la calidad que terminó erigiéndose como en un fin en sí mismo, aunque sí contribuyó a meter al mercado dentro del Estado, por medio de contratos, asesorías, pero sobre todo insertando la lógica de funcionamiento de la empresa dentro de la administración pública.

Igual que en otros países, en México la calidad en la administración pública se ha aplicado a partir de modelos o como certificación ISO, a lo largo de 24 años (1987-2011), y resalta particularmente el auge del periodo 2000-2006, pero ha resultado en grandes contradicciones porque las iniciativas e instrumentos de calidad resultaron costosos y han contribuido a imprimir mayor complejidad al funcionamiento de la administración pública pues han requerido el establecimiento de comités de calidad y la respectiva estructura.

La experiencia también ha mostrado que las soluciones de la administración de la calidad, y calidad total son progresivas, y que su construcción es limitada en los aspectos "contextuales y situacionales", lo que lleva a reflexionar sobre las diferencias entre los países, particularmente en la forma en que está estructurada y organizada su administración pública. Estas diferencias se erigieron en una gran barrera que enfrentó la aplicación de la gestión de calidad. ISO es pues un método para estandarizar las actividades de la empresa, y que si algo no ha sido útil para mejorar la administración pública son los intentos de estandarización con moldes generales.

Asimismo, las etapas que conlleva la certificación y sus costos, son onerosos, pues hay que erogar recursos por diversos conceptos como consultoría externa, consultoría y asistencia; auditorías externas de implantación y seguimiento, pagos anuales o semestrales por concepto de implantación, seguimiento, documentación, y renovación, así como indemnizaciones por gastos de viaje de auditores, incentivos a la productividad, o compensación al personal involucrado en los procesos de implantación del Sistema de la Calidad. A esto se agregan el pago de horas extraordinarias para el personal que participa en los grupos de trabajo y en la implantación del sistema, la utilización de materiales y lugares de trabajo, el tiempo que el personal desatiende sus tareas principales y cotidianas para realizar los trabajos dirigidos a la certificación, y que genera atrasos en sus funciones (FEMP 2003: 64). 
Así pues, en la administración pública ha sucedido que la aplicación de medidas e instrumentos dirigidos a incrementar la calidad, bajo la propuesta de la Nueva Gerencia Pública, distan de cumplir con la expectativa de ahorro de recursos, agilización y eficiencia, y la flexibilización, y más bien se sumaron a la complejidad ya existente, pues la gestión de la calidad requiere que todas las actuaciones implicadas en la prestación de cualquier servicio se documenten, para asegurar que las tareas siempre se hagan igual, independientemente de tiempos o individuos. Esto genera una acumulación de todo tipo de documentos, complejos y simples ha obstaculizado la prestación de servicios. De igual modo, el establecimiento de "comités de calidad", ha precisado la asignación de personal y recursos para dar continuidad al "impulso permanente de la cultura de la calidad" (Federación Española de Municipios y Provincias 2003: 65). Al final de cuentas, se ha llegado a la conclusión de que el procedimiento se ha constituido como un fin en sí mismo, no como medio de servicio al ciudadano.

Sin duda hay mucho que cambiar y mejorar en la administración pública, el punto es qué referente tomamos para hacerlo. Particularmente en el caso de los modelos de calidad y la certificación cabe preguntarse, ¿¿Por qué dentro de la administración pública no se genera la capacidad para lograr que exista orden, sistematización y coherencia en los procesos de gestión? ¿Por qué se tiene que recurrir a empresas privadas que tienen escasos conocimientos sobre la forma en que funciona la administración pública y los verdaderos objetivos a que obedece?, ¿Por qué ostenta mayor coerción una empresa privada, a la que se le tiene que pagar, que la autoridad de un Presidente o de un Secretario de Estado para lograr que dentro de la administración pública los procesos de gestión mejoren? Y finalmente, ¿̇por qué se tiene que pagar para que se den instrucciones de cómo hacer un trabajo que de antemano debería estar bien hecho? 


\section{REFERENCIAS}

Auditoría Superior de la Federación (ASF) (sin fecha). Sistema de Gestión de Calidad ISO 9001:2008 en la ASF. Disponible http://www.asf.gob.mx/Publication/49_Sistema_de_Gestion_de_Calidad_ISO_9001_2008_en_la_ASF [2-72011].

Auditoria Superior de la Federación (2009). Informe Trimestral de Adquisiciones y Obra Pública, Abril - Junio. Disponible en http://www.asf.gob.mx/trans/Obliga/ adqabrjun09.pdf [15-5-2012].

Barzelay, M. (1992). Breaking through Bureaucracy: A New Vision for Managing in Government. Berkeley: University of California Press.

Burgos, F. (1994). Manual. Normas y Técnicas para la Calidad de los Bienes y Servicios en la Industria y el Comercio. México: Universidad Nacional Autónoma de México.

Cámara de Diputados (2008). Segundo Informe de Gobierno, Eficacia, Eficiencia Gubernamental, Transparencia y Rendición de Cuentas. México: Cámara de Diputados. Disponible en http://www.cefp.gob.mx/intr/boletin/boletin2008/bolcefp1172008.pdf [20-4-2011].

(2009). Ley Federal sobre Metrología y Normalización, $1^{\circ}$ de Julio de 1992. Diario Oficial de la Federación (México). Texto vigente, última reforma publicada en el DOF 30-04-2009.

Casals, E. (2005). La Calidad en las Administraciones Públicas en el Contexto Internacional. Disponible en http://www.larioja.org/npRioja/upload/documents/430672_45_ponencia_emilio_casals.pdf;jsessionid=ebe7449b35022874 7dda4a3eb21f:u7+w [2-8-2010].

Centro Latinoamericano de Adminsitración para el Desarrollo (CLAD) (2009). Carta Iberoamericana de Calidad en la Gestión Pública. ICAP-Revista Centroamericana de Administración Pública, 56-57, 363-388.

Consejo Técnico del Premio Nacional de Calidad (2005). Modelo Nacional para la Calidad Total, Presidencia de la República. México: Premio Nacional de Calidad.

Correa, E. (1998). Crisis y Desregulación Financiera. México: UNAM-IIE/Siglo XXI.

Consejo Nacional de Ciencia y Tecnología (Conacyt) (2006). Informe General del Estado de la Ciencia y la Tecnología 2006. México: Conacyt.

Diario Oficial de la Federación (1999). Autorización para Operar como Entidad Nacional de Acreditación a la Asociación Civil Denominada Entidad Mexicana de Acreditación, A.C. (EMA). Secretaría de Comercio y Fomento Industrial, 15 de enero. 
Origen y Efectos de las Normas de Calidad en la Administración Pública

Duménil, G. y Levy, D. (2007). Crisis y Salida de la Crisis. Orden y Desorden Neoliberales. México: Fondo de Cultura Económica.

Dommartin, A. (2003). El Modelo de Calidad Total en los Gobiernos: Innovación y Calidad. Politica Digital, 13. Disponible en http://www.politicadigital. com.mx/?P=leernota\&Article=2209\&c=9 [1-5-2012].

Entidad Mexicana de Acreditación, A.C. (2006). Estatutos Sociales. México: Entidad Mexicana de Acreditación, A.C.

Federación Española de Municipios y Provincias (FEMP) (2003). Pautas para la Aplicación de las Normas ISO 9000 en las Corporaciones Locales: DTSMR_001_00. Madrid: Federación Española de Municipios y Provincias.

Fundación Iberoamericana para la Gestión de la Calidad (FUNDIBEQ) (sin fecha). Misión, Fundación Iberoamericana para la Gestión de la Calidad. Disponoble en http://www.fundibeq.org/opencms/opencms/PWF/fundibeq/mission/ index/index.html? __setlocale=es [22-7-2010].

Galbraith J. (1972). El Nuevo Estado Industrial. Barcelona: Ariel.

Higgins, W. (2006). How We are Governed Now: Globalisation, Neo-Liberal Governmentality and the Nullification of Substantive Policy. Journal of Australian Political Economy, 57, 5-29.

Gobierno de los Estados Unidos Mexicanos (2007). Plan Nacional de Desarrollo 2007-2012. México: Gobierno de los Estados Unidos Mexicanos, Presidencia de la República.

Gobierno Federal de México (2008). Programa Especial de Mejora de la Gestión en la Administración Pública Federal 2008-2012. México: Gobierno Federal.

Guerrero, O. (1999). La Nueva Gerencia Pública. México: Fontamara.

Instituto de Investigaciones Eléctricas (IIE) (2002). La Red de Calidad del Gobierno Federal y sus Perspectivas de Crecimiento. Entrevista con el Ing. Julián Adame, Coordinador de la Red de Calidad del Gobierno Federal. Boletín IIE, julio agosto de 2002, 149-150. Disponible en http://www.iie.org.mx/bolISO02/ energia1.pdf [7-5-2012].

López, J. (1998). La Gestión de la Calidad en la Administración Local. Barcelona: Diputación de Barcelona.

Malvicino, G. (2001). La Gestión de la Calidad en el Ámbito de la Administración Pública. Potencialidades para un Cambio Gerencial. Ponencia presentada en el VI Congreso Internacional del CLAD sobre la Reforma del Estado y la Administración Pública, Noviembre, Buenos Aires. 


\section{VICHER}

Márquez, D. (2007). Calidad en la Administración Pública. La Aplicación de las Normas de la International Organization for Standarization (ISO) a la Administración Pública, México: Fondo Editorial Jurídico.

Medellín, P. (1994). La Modernización del Estado en América Latina: Entre la Reestructuración y el Reformismo. Reforma y Democracia. Revista del CLAD, 2: 67-114.

Merino, M. (2009). Informe sobre la Evolución y el Desempeño de la Auditoría Superior de la Federación. Disponible en http://www.asf.gob.mx/uploads/47_Estudios_especializados/080310ATT90807.pdf [1-5-2012].

Muñoz, R. (2001). Modelo Estratégico para la Innovación Gubernamental. México: Gobierno de la República, Oficina de la Presidencia para la Innovación Gubernamental.

Organización para la Cooperación y el Desarrollo Económico (OCDE) (1991). La Administración al Servicio del Público. Madrid: Ministerio para las Administraciones Públicas.

(1996). Un Gobierno Alerta. Iniciativas de Calidad en la Administración. México: Gobierno del Distrito Federal.

OCDE. París: OCDE.

(1997). Administración Pública: Modelos de los Países de la

Osborne D. y Gaebler, T. (1994). Un Nuevo Modelo de Gobierno. Como Transforma el Espiritu Empresarial al Sector Público. México: Gernika.

Pasha, H. (2003). Perspectivas y Posibilidades de la Calidad en los Gobiernos, Innovación y Calidad. Politica Digital, 13. Disponible en http://www.politicadigital.com.mx/?P=leernota\&Article=2209\&c=9 [1-5-2012].

Presidencia de la República (2003). Tercer Informe de Gobierno. México: Talleres Gráficos de México.

Talleres Gráficos de México.

(2004). Cuarto informe de Gobierno. México: (2005). Quinto Informe de Gobierno. México:

Talleres Gráficos de México.

Talleres Gráficos de México.

(2006). Sexto Informe de Gobierno. México: . (2007). Primer Informe de Ejecución del Plan Nacional de Desarrollo 2007-2012. Disponible en http://pnd.calderon.presidencia.gob.mx/pdf/PrimerInformeEjecucion/1_5.pdf [7-5-2012]. 
Origen y Efectos de las Normas de Calidad en la Administración Pública Talleres Gráficos de México. (2009), Tercer Informe de Ejecución. México: (2010). Cuarto Informe de Ejecución. México: Talleres Gráficos de México.

Real Academia Española. (1729). Diccionario de la Lengua Castellana, en que se Explica el Verdadero Sentido de las Voces, su Naturaleza y Calidad, con las Phrases o Modos de Hablar, los Proverbios o Refranes, y Otras Cosas Convenientes al Uso de la Lengua. Madrid: Imprenta de Francisco del Hierro.

Viuda de Ibarra. (1803). Diccionario de la Lengua Castellana. Madrid: (1914). Diccionario de la Lengua Castellana por la Real Academia Española. Madrid: Imprenta de los Sucesores de Hernando.

Española. Madrid: Espasa-Calpe. (1950). Diccionario Manual e Ilustrado de la Lengua (1970). Diccionario de la Lengua Española. Madrid: Espasa-Calpe.

pañola. Disponible en http://buscon.rae.es/draeI/SrvltConsulta?TIPO_ BUS=3\&LEMA=calidad [Consultado el 12/05/10].

Ruiz, J. (2003). CAF: Una Metodología Europea de Autoevaluación para Mejorar las Organizaciones Públicas. Bits: Boletín Informativo Trabajo Social, 5. Disponible en http://dialnet.unirioja.es/servlet/articulo?codigo=713064 [30/07/2010].

Sánchez, A., Rincón, M. y González, F. (2005). Modelo de Calidad INTRAGOB. Disponible en http://innova.fox.presidencia.gob.mx/archivos/8/8/3/files/ archivos/sip-2944.pdf [21-2-2010].

Secretaría de Economía. (2008). Organismos de Certificación de Sistemas de Calidad. Dirección General de Normas, Actualización al 30 de Agosto de 2008. Disponible en http://www.economia.gob.mx/swb/work/models/economia/Resource/440/1/images/Org_cert_Calidad.pdf [20-05-2010].

Secretaría de Hacienda de Chiapas (sin fecha). Misión, Visión y Objetivos. Disponible en http://www.adquisiciones.chiapas.gob.mx/mision.asp [10-3-2011].

Weiss, M. D. (2009). El Colapso de California. Disponible en http://trinityatierra.wordpress.com/2009/06/24/el-colapso-de-california/ [06-22-2009]. 
VICHER

Yates, J. y Murphy, C. (2006). From Setting National Standards to Coordinating International Standards: The Formation of the ISO. Business and Economic History On-Line, 4. Disponible en http://www.thebhc.org/publications/BEHonline/2006/yatesandmurphy.pdf [9-8-2010].

Recibido: 06-07-2011

Aceptación de la versión final: 08-05-2012 